\title{
Ecology of the North Sea: problems, successes, failures, future needs
}

\author{
O. Kinne \\ Ecology Institute; Nordbünte 23, D-21385 Oldendorf/Luhe, Germany
}

\begin{abstract}
After defining 'ecology', outlining the basic categories of ecological research and listing examples of modern ecological investigations, this introductory paper focusses on basic considerations; it is, in essence, a programmatic contribution. Research details on the ecology of the North Sea are the subject of the following papers. The problems of ecological North Sea research are formidable. Hydrological and biological fluctuations and variabilities are pronounced. Exchange patterns with the Atlantic are complex, and the inputs of rivers and rain defy exact measurement and prediction. Season, weather, climate - and as yet insufficiently known and controlled human-caused impacts - further complicate the situation. All this results in an unusually high degree of uncertainty. New questions and problems arise before the old ones can be answered or solved. Nevertheless, ecological North Sea research has achieved many successes. The North Sea is the most intensively investigated sea area on our planet. Generations of zoologists, botanists and hydrographers - and more recently microbiologists, meteorologists, climatologists, chemists, pathologists and toxicologists - have produced an impressive body of knowledge. Slowly we are beginning to understand the forces that govern energy budgets and balances, material fluxes, and the factors that control and direct ecosystem dynamics. Essential driving forces of ecosystem dynamics result from microbial, especially bacterial, activities. Ecological modelling has paved the way for new theories and insights, and holds promise for progress towards a predictive ecology. Failures and shortcomings include insufficient long-term research, inadequately designed experiments, and misconceptions in environmental protection. Net changes in ecological processes of an heterogeneous and intensely varying environment such as the North Sea can only be comprehended adequately against the background of sustained measurements over decades. Future needs include: more long-term research; and new patterns of management, institutional organization and financial support. Essential breakthroughs in field-work demand more teamwork, in-situ experimentation and surveys from space. Studies on the health status of organisms and ecosystems should receive more attention. Finally, there is need for changes in human behaviour: we must use our insight and willpower to meet the deadly consequences of our self-made scientific-technological evolution by an equally selfmade ethical evolution aimed at achieving a re-harmonization with nature.
\end{abstract}

\section{INTRODUCTION}

This introductory paper focusses on principal considerations. Details of North Sea ecology are the topics of the following contributions.

After presenting a definition of 'ecology', I address problems and obstacles that render ecological research in the North Sea difficult; highlight the major successes achieved; list and analyze essential failures; and outline future needs, i.e. the requirements for correction and improvement. 
'Ecology' has been defined in numerous, if mainly similar, ways. For me 'ecology' involves investigations of interactions between organisms and their non-living environment, and between coexisting forms of life. Ecology is a focal area and interpretive basis for the conceptual integration of information obtained in other life sciences. Today's ecology represents the present status of evolution - the time-related change of living and non-living matter. Or the other way round: evolution is ecology in the fourth dimension time. Both ecology and evolution entail extraordinarily complex, integrated system processes. No living system evolves outside the context of its environment or other living systems. Consequently, the structures and functions of co-evolving organisms and ecosystems constitute the essence of ecological research.

The basic categories of ecological research are taxonomy; descriptive, comparative and empirical field studies; in-situ and laboratory experimentation; and the construction of mathematical models attempting to simulate, quantify, and analyze ecological structures and processes. Combinations of these methods are essential for achieving the best possible understanding of nature.

Examples of modern ecological research are: (1) analysis and quantification of flow patterns, balances and budgets of energy and matter as these pass through organisms, populations and ecosystems; (2) processes of system dynamics, integration and homeostasis; (3) biodiversity, variability and natural fluctuations of ecosystem components; (4) human-caused impacts: their role as modifiers and deformers of living systems, their specific ecological consequences, and their restriction, management and control.

More so than other branches of science, ecology is capable of providing information instrumental to understanding, managing and protecting living systems. Ecology provides the keys for defining measures intended to control and guide human influences on nature, for planning our own future, and for securing the long-term survival of the overall system 'nature plus Homo sapiens'. Hence, ecology also includes components of ethics.

\section{PROBLEMS}

The North Sea is a unique aquatorium with hydrographic and biological features that render ecological research difficult. Water movements and exchanges with the Atlantic, climate interrelations, and inputs from rivers ${ }^{1}$, rain and ground water result in considerable variations and fluctuations, and are difficult to assess. Powerful impacts from human activities, especially fisheries and pollution, further complicate the picture. The quantity and quality of human-caused changes are difficult to determine, and the exact definition and registration of many of the chemical species and compounds involved in pollution not to speak of their in-situ transformations, interactions and ultimate effects on living systems - still defy detailed analysis. All this results in an unusually high degree of uncertainty. Add the lack of sufficient ecological base-line data and the still incompletely known and understood natural long-term fluctuations of physical, chemical and biological parameters, and your have a situation which challenges the best minds and the most sophisticated equipment.

\footnotetext{
' In its size class, the Elbe is the most heavily contaminated river in Europe. Over decades it has carried vast amounts of pollutants into the southern North Sea
} 
The North Sea is surrounded by densely populated, highly-industrialized nations. Together, these inflict gigantic forces of modification, deformation and destruction upon the marine biota. The North Sea is used especially for fisheries, waste disposal, oil drilling, transportation and recreation. The interests of the users differ and are often conflicting.

In the face of all these problems, present efforts of ecological research and environmental management in the North Sea, and the amount of pertinent financial support, are inadequate. Human-caused deformations of North Sea ecosystems continue to increase, and this trend is likely to persist, at least for a considerable time. New questions and problems arise before the old ones can be answered or solved.

\section{SUCCESSES}

The North Sea is the most intensively investigated sea area on earth. Generations of zoologists, botanists and hydrographers - more recently also microbiologists, meteorologists, climatologists, biochemists, pathologists and toxicologists - have produced an impressive body of knowledge. More than a century ago, i.e. before the Biologische Anstalt Helgoland was founded, naturalists began to sample organisms, sediment and water. They focussed their attention on taxonomy, life cycles, descriptive and comparative field studies, fisheries, organismic distributions and abundances. In essence, this research was an attempt to take stock. It produced the foundations on which today's structure of North Sea ecology could be erected step by step. While this early type of research continues up to the present, studies of ecosystem dynamics have increasingly dominated the scenario. The conceptual and technological instrumentarium of the marine ecologist has been enlarged and refined, with considerable success. Modern experimental work, both in the sea and in the laboratory, is providing powerful new analytical tools.

Slowly we are beginning to understand some of the major forces and rules that govern energy budgets and balances, material fluxes, and the factors that control and direct ecosystem dynamics, homeostasis and biodiversity.

The development of marine ecological research over the past 100 years is not only characterized by a trend from description to experimentation, and by increasing emphasis on chemistry, physics and mathematics, but also by a trend from large to small. We have become increasingly aware of the fact that essential driving forces of ecosystem dynamics lie in the realm of microbiology: a vast variety of bacteria and other microbial forms dominate, fuel, and direct basic patterns and avenues of production, transformation and decomposition, i.e. govern the processes and paths of material cycling and energy flow. In the darkness of deep waters, bacteria can provide the nutritional basis for a large assortment and multiformity of life forms which we are only now beginning to discover and to study. Deep-sea bacteria utilize terrestrial sources of energy. They drive chemosynthetically fuelled food webs that parallel the better known solar-energy driven food webs in shallower waters and on land. In addition, microorganisms, including chemosynthetic bacteria, play an increasingly recognized role as producers of animal biomass in a variety of symbioses.

In the last few decades, computers have enterea the scene. Modelling and computer simulation are opening up new vistas beyond traditional ecological thinking and allow- 
ing us to venture into complex interdependencies that defy comprehension by our 'naked' brain. Computers enlarge our intellectual capacity, as the microscope enlarges our sense of vision. However, in contrast to the microscope, computers may deliver distorted or outright false pictures - unless they are fed with the right data (which are still rare) and the right programmes (which are often still a matter of debate). Here, closely adjacent, lie possibilities for brilliant breakthroughs - and possibilities for a lot of nonsense.

Ecological modelling has paved the way for pacemaking hypotheses, theories and new insights into the interrelations between ecosystem components. With the still quite limited data at hand on ecological processes in the North Sea, however, it seems more realistic at present to work with a series of area-specific sub-models rather than to aim directly at an in-toto concept.

The successes achieved in mathematical modelling and system theory are beginning to produce a substrate for entirely new perspectives. For the first time in the history of ecological research, a potentially very important new instrument seems within reach: predictive ecology. Even if restricted to generalities, the prediction of ecological events as a result of known principles and rules, as well as variations and disturbances, could offer leads and guidance in the absence of more accurate detailed information that may take a long time to become available.

Successes can also be reported in the recording and assessment of the biological effects of pollutants in the North Sea. Two recent international and multidisciplinary workshops have tested, compared and weighted a wide range of established and new biological techniques for monitoring and evaluating pollution effects. Published in special volumes of 'Marine Ecology Progress Series' (Bayne et al., 1988; Stebbing et al., $1992^{2}$ ), the results of these expert meetings are an important source of information for all those concerned with North Sea pollution.

It is not possible to list here the numerous other successes achieved in ecological North Sea research; but I wish to mention a few selected examples, and I hope you will forgive me that these are taken from contributions by the Biologische Anstalt Helgoland $(\mathrm{BAH})$ - our centenarian.

In 1962 the BAH initiated a research programme ('Schwerpunktprogramm'), aimed at long-term combined in-situ and laboratory research, to be executed by a team of zoologists, botanists, microbiologists and hydrographers (cf. BAH Tgb Nr. 1293, 1963). The intention was to produce essential base-line and cornerstone data for assessing the ecological dynamics in the German Bight and to determine, in cultivation experiments, essential performance characteristics of key species under controlled conditions.

Our team-based, sustained ecological research efforts were supported by the Federal Government in Bonn via the financing of a new research ship, the 'Friedrich Heincke', a new building, the 'Experimentell Ökologische Labor' (a modern multipurpose environmental system; Kinne, 1976), and a number of new positions for scientists and technicians. To this day, the basic concept of the 'Schwerpunktprogramm' dominates the research efforts of the BAH. However, the financial and logistic support available thus far has not sufficed to bring the programme to full fruition. When I conceived and initiated the 'Schwerpunktprogramm' in 1962, the BAH scientists - like most of their colleagues in

\footnotetext{
2 The MEPS SPECIALS are also available in the form of a hard-cover book
} 
comparable institutions - were in essence soloists and not sufficiently prepared and motivated to accept additional roles as team members, i.e. to play in an orchestra. An orchestra, however, that combines different instruments and talents, directed by a conductor, is a prerequisite for tackling essential problems inherent in large, complex and heterogeneous ecological systems such as those in the North Sea. The emphasis here lies on the teamwork of experts with different skills and with long-term commitments. If the 'Schwerpunktprogramm' could have been realized full scale as originally planned, we would now have much more solid base-line data for assessing ecological processes and natural fluctuations and variabilities, as well as human-caused modifications in the southern North Sea. In the meantime, the importance of long-term data has been documented and exemplified by a small remnant of the 'Schwerpunktprogramm': the station 'Kabeltonne Helgoland' ('Zeitreihe Helgoland-Reede'). The importance of longterm ecological research has been emphasized also by others, for example, by Strayer et al. (1986), Franklin (1989) and Franklin et al. (1990). And what concerted, sustained, ecological team research can accomplish has been documented convincingly, years after the initiation of the BAH 'Schwerpunktprogramm', by Gene E. Likens and his team in their famous 'Hubbard Brook Ecosystem Study' (e.g. Likens, 1985, 1992).

I call here for a revival and modernization of the BAH 'Schwerpunktprogramm', for strengthened international and multi-institutional cooperation in North Sea ecology research, and for the installation of a net of automatic stations aimed at surveying and monitoring environmental changes.

Selected examples of important, successful BAH contributions to the study of ecological processes in the North Sea include: in-situ and laboratory experimentation on North Sea animals, plants and microorganisms; ecosystem research in the Wadden Sea near Sylt (e.g. Anonymous, 1991); quantitative studies on the bottom fauna; analyses of predator-prey interrelations of plankters; research on pollution, eutrophication and environmental protection; investigations on the ecophysiological performance of invertebrates and fishes; experiments on photoecology and physiology of algae; computer simulations; work on the cultivation of marine organisms; and on the taxonomy and life cycles of marine species. In recognition of the increasing human impact on the North Sea biota, the BAH organized, in 1967, the first international symposium that addressed problems of biological and hydrographical water pollution in the North Sea (Kinne \& Aurich, 1968). A second international symposium, held in 1979 and entitled 'Protection of Life in the Sea', summarized and evaluated findings reported in the interim (Kinne \& Bulnheim, 1980).

\section{FAILURES}

While the successes in North Sea ecology research are manifold and significant, so also are the failures and shortcomings.

As already emphasized, North Sea research has placed insufficient weight on sustained long-term studies of ecosystem structures and functions. We cannot separate, define and assess ecological changes caused by natural versus human-produced forces, without sufficient knowledge of base-line data and normal, natural ranges of fluctuations and variabilities of essential ecological parameters. We still lack reliable calibration points against which to gauge ecological net changes as a function of time. 
The degree to which ecological processes in the North Sea are modified or deformed due to climate-related factors and changes, or to human-imposed impacts, still awaits differentiation. For example, we do not yet know to what extent disorders of fish, invertebrates, plants and microorganisms can be linked directly to pollution effects, or what are the in-situ tolerance limits of organisms and ecosystems to specific natural and human-caused impacts. Again, I deplore here the failure of politicians, administrators and scientists to fully support the 'Schwerpunktprogramm', developed in 1962 with the aim of providing exactly the kind of data which we now so sorely miss.

There are also failures in the design of experimental laboratory work - at least to the extent that it intends to produce ecologically meaningful data on organismic performances under different, controlled environmental conditions - and on the tolerance limits of selected populations or species to different intensities of natural or human-induced stressors. Such studies are necessary to characterize the ecological and physiological potentials (Kinne, 1980a, p. 755) of the building-blocks of ecosystems: the populations of coexisting species. The shortcomings here are: (1) Most of the information available to date has been obtained from relatively few species, especially those of high commercial value and above-average resistance to stress (euryplastic forms), or species selected for solving a specific research problem, more or less unrelated to ecology. (2) We lack information on a representative spectrum of ecological key species. (3) The organisms examined were often kept under conditions essentially different from those prevailing in nature, offered nutrients they would not normally utilize, and not tested for their health status (many may have been under shock, hurt, sick, infected). (4) More often than not, metabolic performances have been measured during the stabilization phase, i.e. before the tested organism could reach the new steady-state under the conditions provided. How can data obtained under such circumstances be used in good faith for interpreting the behaviour of organisms under field conditions, or for feeding computers in order to simulate natural ecological processes, or to make ecological predictions? I have repeatedly pointed out these failures and shortcomings in the past (cf. Kinne, 1975, p. $2 ; 1984$ a) - to little avail.

Many programmes of environmental protection continue to focus on protecting the human environment. This means nothing else than further shifting the life-supporting qualities of ecosystems in favour of a single form of life - Homo sapiens - and neglecting the requirements of all other coexisting forms, on whose presence and well-being we nevertheless decisively depend. In other words, such environmental protection programmes are part of the detrimental world-wide processes which continuously expand the unique dominance of, and exploitation by, human societies - the very process that made environmental protection, in the sense of protecting the ecological integrity of living systems, necessary in the first place! (Kinne, 1984b, p. 1099). This then is a striking example of a concept conversion, if not perversion: an example of how different human groups adapt, bend and adjust one and the same thing to meet their own, diverging interests.

What we are presently studying in the North Sea is no longer the 'natural' biota but ecosystems under stress, already more or less deformed due to human impacts. We have failed to establish protected areas in time. Projects such as the Naturschutzgebiet Helgoland' or 'Wadden Sea National Parks' came late. They suffer from insufficient conceptual strictness, control and areal size. Protected areas are important as ecological reference areas, recruitment centres for endangered species, and research tools 
Looking beyond North Sea ecology, it is not difficult to bring into focus additional, principal failures. Several of our enterprises exacerbate present problems instead of reducing them: e.g. military activities; shortcomings in energy politics (including nuclear power-plant design, operation and safety); production and discarding of dangerous substances without consulting ecologists and with insufficient efforts towards recycling; rain-forest destruction; ozone depletion; waste of water resources; degradation of land, water and air. Many programmes intended for helping 'developing countries' reflect essential failures in political and administrative planning. Typically, a major aim of such programmes is to support industrialization. Thus, the failures are repeated that led to the present environmental crisis in 'developed countries' with all its negative ecological and social consequences. World-wide, economic success is still measured in terms of growth rates. However, continued growth on a planet with limited dimensions, resources and carrying capacities of ecosystems is unrealistic, to say the least. We have thus far failed to develop a new global concept of economic politics.

Indeed, it is high time to recognize these failures and to act accordingly!

\section{FUTURE NEEDS}

The successes and failures addressed above provide the substratum on which grow the requirements of tomorrow: the needs for correction and improvement. I outline here a few of the more significant needs - some directly related to the North Sea, some of a more general ecological significance, and some reaching into the realm of ethics.

For a proper assessment and better understanding of ecological variabilities, fluctuations and dynamics we need, first of all, carefully designed long-term research. While the performance of soloists is important and must be continued, some of the most burning questions concerning North Sea ecological research can only be tackled by an international, inter-institutional and interdisciplinary team of scientists blending together, for extended periods of time, different talents and expertise. Only team-based, sustained research over decades can provide the required base-line data and achieve significant progress at the very heart of North Sea ecology: the analysis of the flow patterns and routes of energy and matter, the time-space interactions among ecosystem components, the factors involved in achieving and maintaining biodiversity and system homeostasis, and the analysis of human-caused modifications and their consequences for living and non-living ecosystem components. Long-term collection and analysis of qualitative and quantitative field data is also the most important prerequisite for the construction of a solid basis on which sound, testable hypotheses, theories and predictions can grow.

Effective long-term work of scientific teams requires the development of new organizational and logistic structures. The conventional means of operating and supporting classical marine science institutions are no longer adequate for the type of long-term research I have in mind here. Sponsors of scientific research, governmental or private, cannot simply continue to apply the routine methods of short-term financing and success control - not to speak of the often erratic changes in research politics. We need new patterns of research support and goal definition. These must be adjusted to the much longer pulses of sustained long-term research. (On the other hand, uninterrupted, secure long-term funding can create its own problems: loss in stimulation, innovation and motivation, and degeneration into self-serving sterility and progressive unproductivity.) 
There is need for more mesocosm studies and for more in-situ experimentation. The conventional sea-surface-based information gathering should be complemented and augmented by biological oceanography from space (satellite remote-sensing). And there is need for more experimental work in coastal areas, as well as in and beneath the sea. Present instruments for experimental manipulation of natural ecosystem structures and functions in selected areas must be further developed and refined. The basic techniques at hand - intertidal installations, diving, underwater vehicles and underwater laboratories - have already demonstrated their unique value as tools in the hands of marine ecologists. Field experimentation is the most powerful means for testing current ecological ideas, theories and hypotheses, and thus for building the basis of predictive ecology.

We need more information on the health status of individuals, populations, species and ecosystems. Diseases can affect all structures and functions of living systems, at all levels of organization: cellular, tissue, organ, individual, population, species and ecosystem. More knowledge on disease phenomena in marine animals, plants and microorganisms is required for assessing their role in ecosystem dynamics and for employing pathological criteria as indicators of health, stress and human-caused deformation (for details consult the 4-volume treatise 'Diseases of Marine Animals', Kinne, 1980b, 1993, $1984 \mathrm{c}, 1985,1990)$.

We need more actions to protect the diversity of life. Based on thorough inventories of the present biological variety on our planet, the specific actions formulated by Wilson (1992) provide essential guidelines that hold promise for enhancing rather than diminishing biodiversity. As Wilson (1992, p. 281) states: 'Biodiversity is our most valuable but least appreciated resource'.

Ecological concepts, theories and recommendations for environmental protection should be based on combinations of all major avenues of inquiry: natural history, collection of environmental data and organisms, comparative empiricism, experimentation under in-situ conditions and in the laboratory, study of balances and budgets, modelling and computer simulation. And we must also consider all basic components of marine ecosystems: biosphere, hydrosphere, lithosphere and atmosphere, as well as their manifold interactions and interdependencies. The linkages (cf. Likens, 1985) between these components and the transport of energy and matter involved - sometimes over long distances - are crucial for understanding the relations between different ecosystems; they are a prerequisite for a better understanding of world-wide pollution effects and climate dynamics.

We urgently need more and better-qualified personnel in governments and industry for translating ecological findings into effective legislation and regulation aimed at the improvement and acceleration of tailor-made measures to restrict and control environmental degradation.

Other future needs exceed the domain of the ecologist. They involve human behaviour, responsibility and ethics. Without responding to these needs, none of the needs referred to above can effect positive changes in the long run. Human societies impact and dominate life on earth so much that changes in human behaviour and a reduction in human numbers and demands have become imperative. There is not much time. The survival of millions of people demands immediate ${ }_{r}$ effective action. Measures for sustaining the life-supporting qualities of nature must be started now! 
Major initiatives for correction and improvement are expected to come from two groups of people: scientists - especially ecologists - who must explore and define the requirements for the sustained long-term health and integrity of nature; and politicians who must translate these requirements into legislative action, seeking a compromise between the desire to sustain a high living standard for modern human societies and the need to protect nature. The ultimate aim is to secure biodiversity and to conserve the ecological basis for human existence.

Life on earth has evolved in, depends on, and remains constrained by, ecosystems. The basic rules and forces that govern life in ecosystems appear to be the following: (1) Harmonized co-existence of adapting, co-evolving different forms of life, each programmed towards exploitation of all available circumstances that increase its competitive advantages over others. (2) Specialization of system components and - whenever ecologically successful - increasing structural and functional complexity. (3) Maturation of organismic inter-dependencies, diversification, system coordination, and system homeostasis. (4) Development and perfection of safeguards for system survival, e.g. by allowing for loss or addition of components, by avoiding the accumulation of potentially systemendangering substances, and by avoiding the development of potentially system-endangering forms of life (Kinne, 1984a).

Here lies the crux of our dilemma. Within the last century one form of life - Homo sapiens - has managed to evade several of the system's safeguards and to develop a system-endangering potential of a magnitude apparently unique in the history of life on earth. Originating as, and acquiring the genetic programme of, a fully-integrated system member, and operating over millions of years within the system's rules and forces, the modern representatives of our species have disrupted this harmony by explosively multiplying their potential for exploiting all available circumstances that increase their competitive advantages over other species.

We have added to the harmonized ecological co-evolution a new element: a humanmade scientific-technological evolution. In essence, this is based on the invention of language, writing and a formalized process of producing new information (science), as well as the creation of effective mechanisms of storing and evaluating individually acquired information and for transferring it to the next generation (publications, schools, universities). These inventions and improvements in communication facilitated a technological-industrial revolution that is still gaining momentum and is continuously fuelled and catalyzed by forces emanating from world-wide competing economic and political power groups. The technological-industrial revolution causes massive deformation in ecosystems and represents a lethal danger to the survival of many species and of human societies. Its effects are further accelerated and aggravated by an explosion of human population size and an increase in the 'overall metabolic rate' per capita.

In this world, Homo sapiens can play only two principal roles: ecosystem member or ecosystem controller. Integrated ecosystem member we are no more, ecosystem controller not yet. The role of an ecosystem controller requires properties essentially different from those of an ecosystem member. What is needed here - in addition to more scientific knowledge - are ethical properties: the acceptance of responsibility for our actions, and self-restriction. There are no natural evolutionary processes that select for ethical properties. Responsibility and self-restriction are foreign to nature (Kinne, 1984a). In fact, there does not seem to be a place in nature's design for a human erosystem controller. Over 
billions of years the role of ecosystem controller has been played successfully and effectively by nature herself.

Here we are: a species whose every cell is genetically programmed for its role as integrated ecosystem member, but with a non-genetically acquired destructive capacity far beyond any system harmony, and to a large extent already outside the system's safeguards and control mechanisms. There is only one way out of this dilemma: we must use our insight and willpower to match the deadly consequences of our self-made scientific-technological evolution by an equally self-made ethical evolution aimed at achieving a re-harmonization with nature. Indeed, a titanic challenge!

\section{LITERATURE CITED}

Anonymous, 1991. Interdisziplinäre Forschung: Wattenmeerökologie.- Jber. Biol. Anst. Helgoland $1990,86-86$.

Bayne, B. L., Clarke, K. R. \& Gray, J. S. (Eds.), 1988. Biological effects of pollutants. - Mar. Ecol. Prog. Ser. (MEPS Special) 46, 1-278.

Franklin, J.F., 1989. Importance and justification of long-term studies in ecology. In: Long-term studies in ecology. Ed. by G. E. Likens. Springer, New York, 3-19.

Franklin, J.F., Bledsoe, C.S. \& Callahan, J.T., 1990. Contributions of the long-term ecological research program. - Bioscience 40, 507-523.

Kinne, O., 1975. Introduction to Volume II. In: Marine ecology. Vol. 2, P. 1: Physiological mechanisms. Ed. by O. Kinne. Wiley, London, 1-8.

Kinne, O., 1976. Cultivation of marine organisms: water-quality management and technology. In: Marine ecology. Vol. 3, P. 1: Cultivation. Ed. by O. Kinne. Wiley, London, 19-300.

Kinne, O., 1980. 14th European Marine Biology Symposium: Protection of Life in the Sea: Sum. of symposium papers and conclusions. - Helgoländer Meeresunters. 33, 732-761.

Kinne, O. (Ed.), 1980b. Diseases of marine animals. Wiley, Chichester 1, 1-466.

Kinne, O. (Ed.), 1983. Diseases of marine animals. Biologische Anstalt Helgoland, Hamburg 2, 468-1038.

Kinne, O., 1984a. Ökologie - Brennpunkt biologischer Forschung und Schicksalsfrage für die Menschheit. In: Karl Ritter von Frisch-Medaille. Wissenschaftspreis 1984 der Deutschen Zoologischen Gesellschaft. Hrsg. von G. Peters. Fischer, Stuttgart, 24-37.

Kinne, O., 1984b. Introduction to Part 3 - Pollution and protection of the seas: radioactive materials, heavy metals, and oil. In: Marine ecology. Vol. 5, P. 3: Ocean management. Ed. by O. Kinne. Wiley, Chichester, 1091-1110.

Kinne, O. (Ed.), 1984c. Diseases of marine animals. Biologische Anstalt Helgoland, Hamburg 4,1, $1-541$.

Kinne, O. (Ed.), 1985. Diseases of marine animals. Biologische Anstalt Helgoland, Hamburg 4,2, $543-884$.

Kinne, O. (Ed.), 1990. Diseases of marine animals. Biologische Anstalt Helgoland, Hamburg 3, $1-696$.

Kinne, O. \& Aurich, H. (Eds.), 1968. International Symposium 1967. - Helgoländer wiss. Meeresunters. $17,1-530$.

Kinne, O. \& Bulnheim, H.-A. (Eds.), 1980. 14th European Marine Biology Symposium: Protection of Life in the Sea. - Helgoländer Meeresunters. 33, 1-772.

Likens, G. E., 1985. (Ed.) An ecosystem approach to aquatic ecology: Mirror Lake and its environment. Springer, New York, 516 pp.

Likens, G. E., 1992. The ecosystem approach: its use and abuse, In: Excellence in ecology. Ed. by $O$. Kinne. Ecology Institute, Oldendorf, $166 \mathrm{pp}$.

Stebbing, A. R. D., Dethlefsen, V. \& Carr, M. (Eds.), 1992. Biological effects of contaminants in the North Sea. - Mar. Ecol. Prog. Ser. (MEPS special) 91, 1-361.

Strayer, D., Glitzenstein, J. S., Jones, C. G., Kolasa, J, Likens, G. E., McDonnell, M. J., Parker, G. G: \& Pickett, S. T.A., 1986. Long-term ecological studies: an illustrated account of their design, operation, and importance to ecology. - Occ. Publs. Inst Ecosystem Stud. 2, 1-38.

Wilson, E. O., (Ed), 1992. The diversity of life. Belknap Press, Cambridge, 424 pp. 